\title{
Evaluation on simulation training for midwifery science trainers in Windhoek, Namibia
}

\author{
Emma Maano Nghitanwa, Tuwilika Endjala, Saara Kerthu Hatupopi \\ Midwifery Department, School of Nursing, University of Namibia, Namibia
}

Received: January 30, 2019

Accepted: April 20, 2019

Online Published: August 23, 2019

DOI: $10.5430 /$ jnep.v9n11p47

URL: https://doi.org/10.5430/jnep.v9n11p47

\begin{abstract}
Simulation training refines skills needed to correct mistakes by allowing trainees to fine tune their skills. To improve the knowledge and skills of the midwifery educators, a simulation training has been organised for them so that they are able to provide simulation to the students. This was in part necessitated by the understanding/observation that students tend to be less anxious at the clinical practice after they had simulation training. A quantitative, cross-sectional study design was employed. Data was collected with structured self-administered questionnaires among 10 midwifery trainers who attended a simulation training workshop. This workshop was conducted by trainers from Cardiff University under the Phoenix project in June 2016. Due to the limited number of trained educators, census sampling method was used and data was analysed using SPSS version 25 . The study results indicated that most midwifery educators are female within middle age category. Most participants have attended simulation training before and have been conducting simulation to students. Furthermore, most participants indicated that they were satisfied with the training and that they gained knowledge and skills on simulation that they can utilize during student training. The researchers recommend further research on evaluation of knowledge and skills such as evaluating participants on simulating procedures.
\end{abstract}

Key Words: Educators, Midwifery, Simulation, Training

\section{INTRODUCTION}

In midwifery training, simulation is highly being used as a teaching tool for the improvement of management of emergency cases and improvement of competence and confidence in practical skills. ${ }^{[1]}$ Simulation is defined as activities that imitate the reality of a practical or clinical environment designed to demonstrate clinical procedures by using technical devices such as interactive videos or mannequins. During simulation, the simulator is able to make decisions as well as thinking critically. ${ }^{[2]}$

Simulation aims to imitate reality as well as offering skillsbased clinical experience in a safe and secure environment and to diminish the gap between theory and practice. ${ }^{[3]}$ Furthermore, simulation replicates essential aspects of a clinical situation so that the situation may be more readily understood and managed when it occurs in a real situation in a clinical practice. ${ }^{[4]}$ For the simulation to be effective, aspects of simulation such as briefing, good communication, observation (witnessing peers/being observers), repetition, reflection/debriefing and evaluation should be emphasised. ${ }^{[1]}$ Simulation based teaching is useful in midwifery training to ensure the intensive skill practice, fill skill teaching gaps and to safeguard human patients. ${ }^{[5]}$ Psychomotor technical skills development is critical for safe midwifery practice, ${ }^{[6]}$

\footnotetext{
* Correspondence: Emma Maano Nghitanwa; Email: enghitanwa@ unam.na; Address: Midwifery Department, School of Nursing, University of Namibia, Namibia.
} 
which could be attained through proper simulation training of midwifery trainers. ${ }^{[7]}$ It is necessary for Midwifery students to be skilful at the highest level before entering into the health care system which could be attained through proper simulation training of midwifery trainers. ${ }^{[8]}$

Gudayu et al. ${ }^{[5]}$ highlighted the four key facets which support the effectiveness of using simulation training in midwifery education, such as developing technical proficiency through practice of psychomotor skills and repetition, assistance of experts which is tailored to students' needs, situated learning within context, and incorporation of the emotional component of learning. Moreover, it was found out that simulation design clear learning objectives, and an appropriately challenging problem were all significantly correlated with students' satisfaction and self-confidence during simulation training. ${ }^{[9]}$ In Namibia, simulation training is used at training institutions before students go for clinical placement where low fidelity simulators are used during simulation sessions. This assists students to integrate theoretical knowledge into practice and develop their psychomotor skills.

Midwifery trainers should therefore be trained on proper simulation technique so that they can effectively transfer the same knowledge and skills to students. Therefore, this study was conducted in order to evaluate the outcome of the simulation training given to midwifery educators. The School of Nursing at the University of Namibia is utilising simulation training to facilitate learning of student nurse/midwives. Simulation training should be realistic, patient-focused, structured, and grounded in an authentic clinical context. Simulation-based training was conducted for trainer at the University of Namibia in June 2016; however, no study has been conducted after the training to assess the effectiveness of the training. Furthermore, although several literature on simulation exisit, no study was conducted on simulation training in Namibia. This therefore warrants the need for an evaluation of the simulation based training to be conducted.

\section{Objectives}

The objectives of this study are to:

- Assess the socio-demographic characteristics of midwifery educator in Namibia

- Determine the reaction of midwifery educators towards simulation training

- Assess the behavioural change of midwifery educators after the simulation training

\section{METHOD}

A quantitative, cross-sectional study design was employed and the study was conducted in June 2017. The study popu- lation comprised of midwifery educators from higher institutions of learning in Namibia such as; University of Namibia, International University of Management, Ministry of Health and Social Services Training Center and Welwitchia Training center. Trainers from Cardiff University under the Phoenix project conducted the workshop in June 2016. The content of the study consisted of the following key components; planning and demonstrate skills teaching session on breech birth, suturing a perineum, shoulder dystocia, manual removal of the placenta and bimanual compression of the uterus; Plan a case based discussion Post-Partum Haemorrhage; Scripting and facilitating a simulation scenario and Debriefing. Fifteen midwifery trainers were trained. Two researchers were part of the trained group. Census sampling method was used due to the limited number of trained educators. All eligible midwifery educators were included in the study, but only 10 midwifery educators agreed to participate. The questionnaire was developed and adopted by the researchers from the Kirkpatrick's learning evaluation model (1959). Data was collected with the structured questionnaire which consisted of a Likert scale with five (5) items for the participants to tick the necessary rate such as Strongly agree, Agree, Uncertain, Disagree and Strongly disagree. The structured and pretested questionnaire was used to collect data regarding socio-demographic characteristics, training satisfaction, selfconfidence in learning, and knowledge gained from the training. All data collection tools were checked for completeness and consistency. Data was coded and entered into data set and analysed using SPSS version 25. Frequencies. Proportions were used to describe categorical data and means and standard deviation were used for continuous data. Descriptive statistics is presented in frequency tables and graphs.

\section{Ethical consideration}

Ethical clearance was obtained from the University of Namibia research ethical clearance committee. Participants were informed about the purpose and objectives of the study and their rights to discontinue or refuse to participate in the study without getting any punishment. Confidentiality and anonymity of the collected data was ensured at all times. Participants were requested to sign the informed consent to confirm their willingness to participate in the study. No compensation was given to the participants. Data was password protected.

\section{RESULTS}

3.1 Socio-demographic characteristic of participants

Ten participants who participated in the study were aged between 31 and 60 years. The mean age was 49 years. Among participants $6(60 \%)$ were within the age group of 31 to 49 years while $4(40 \%)$ represented the age between54 to 60 
years. All participants were female. Regarding participants positions at their training institutions, more than half $(60 \%)$ of the participants were lecturers, followed by 2 (20\%) clinical instructor and assistant lecturer, whereas tutors were represented by only $1(10 \%)$ respectively.

\subsection{Simulation training background}

Participants were asked to indicate the times they simulate to the midwifery students. In this regard, as displayed in Figure 1, 6 (60\%) indicated that they simulate weekly, 2 (20\%) stated that they simulate once a month while $2(20 \%)$ surprisingly indicated that they do not simulate as they were excluded from simulations and only teach midwifery theory.

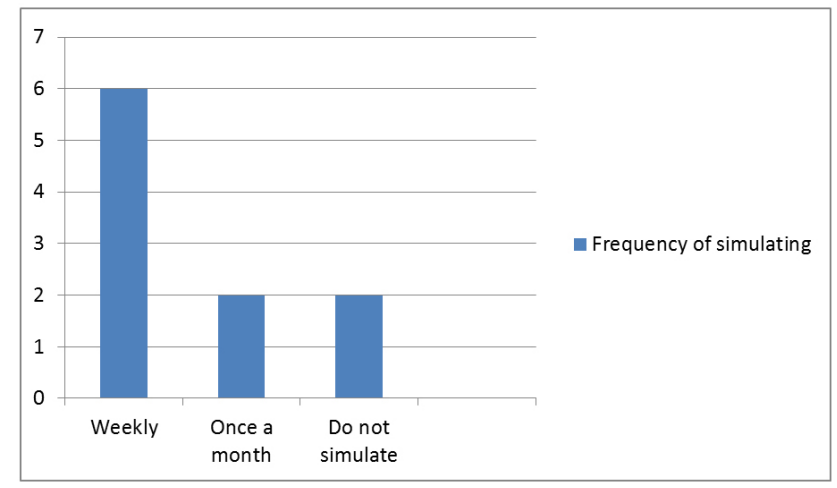

Figure 1. Frequency of simulating to midwifery students

All participants have indicated that they have attended the simulation training for trainer workshop. Regarding the last time they participated in the simulation training for trainer workshop, $5(50 \%)$ participants indicated that they have attended before August 2015, and 2 (2\%) equally have indicated that they have attended for the first time during the Phoenix project training and in 2015. However, $1(10 \%)$ of the participants has indicated having attended the simulation training for trainers within the last six (6) months. Results are displayed in Figure 2.

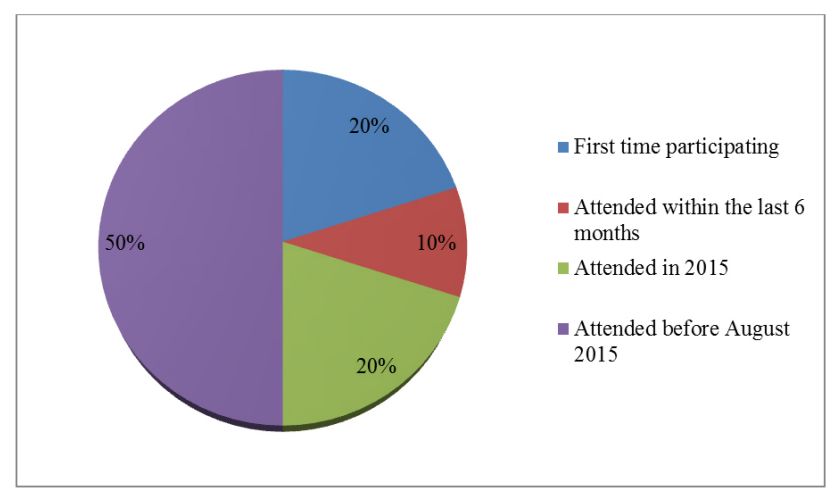

Figure 2. Last time participant participated in simulation training

Published by Sciedu Press

\subsection{Satisfaction on training}

Participants were asked to rate whether the teaching methods used in the simulation training were helpful. Half of the participants agreed and another half strongly agreed.

Regarding whether the simulation training provided the participants with different learning materials to promote learning, $70 \%$ of the participants agreed and 30\% strongly agreed. Participants were equally asked to indicate how the activities used during simulation training motivated third learning. In this regard, $40 \%$ of the participants agreed and $60 \%$ strongly agreed. Furthermore, 50\% of the participants agreed and strongly agreed that the instructors used helpful resources to teach the simulation.

Regarding whether the simulation scenarios seemed realistic, the majority of the participants (70\%) strongly agreed and $30 \%$ agreed. Similarly, $70 \%$ of the participants indicated that the actors seemed realistic and 30\% agreed. Participants were also requested to rate equipment provided during the simulation if they seemed realistic where the majority $(70 \%)$ have strongly agreed while $30 \%$ agreed. Regarding whether participants felt like they were involved in a real clinical situation, $70 \%$ strongly agreed and 30\% agreed.

\subsection{Self-confidence in learning}

Regarding whether participants felt confident that the training covered critical content for the mastery of midwifery science curriculum, $50 \%$ of the participants strongly agreed, $40 \%$ agreed while $10 \%$ strongly disagreed. In addition, $60 \%$ of the participants agreed that they were confident to debrief, $30 \%$ strongly agreed while $10 \%$ disagreed that they were not confident in debriefing as shown in Figure 3.

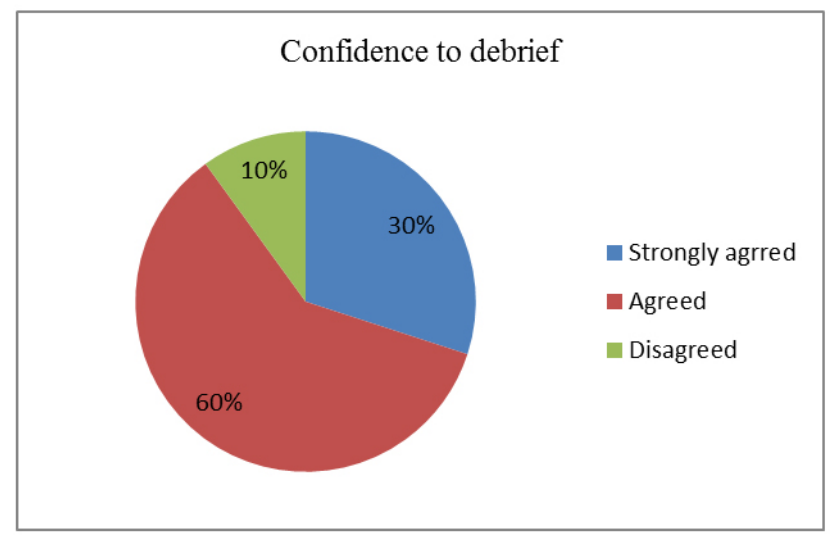

Figure 3. Confidence to debrief

\subsection{Knowledge aimed from training}

The majority (70\%) of the participants strongly agreed that they learnt something new during the simulation training and $30 \%$ agreed as depicted in Table 1 . 
Table 1. Participants views on new learned skills during simulation training

\begin{tabular}{lll}
\hline $\begin{array}{l}\text { Simulation provided me with new } \\
\text { learning skills }\end{array}$ & Frequency & $\begin{array}{l}\text { Percent } \\
\text { (\%) }\end{array}$ \\
\hline Agree & 7 & 70 \\
Strongly agree & 3 & 30 \\
Total & 10 & 100 \\
\hline
\end{tabular}

In a nutshell, $60 \%$ of the participants have agreed that their perception on simulation preparation has improved while $40 \%$ strongly agreed. On the statement whether participants felt that the training increased their confidence on training students on emergencies in labour, participants responses were equally split between agreed and strongly agreed.

Participants were also requested to indicate whether the simulation training has improved their ability to work in a team, where $60 \%$ strongly agreed and $40 \%$ agreed.

Regarding whether participants experienced any challenges in simulation training using the Phoenix project model; the majority $(90 \%)$ indicated that they never experienced any challenge. However, $10 \%$ of the participants indicated that due to the higher number of students they were challenged to effectively simulate to the students using the Phoenix project model.

\section{Discussion}

Clinical simulation-based education is an important aspect in nursing and midwifery education as it creates a specific learning environment to ensure nursing and midwifery students competency by reinforcing their clinical skills through different levels of competency. ${ }^{[10]}$ Errors in the healthcare system are occurring at an alarming rate as many new graduates are not prepared to deal with the complex patient situations, they encounter in the work setting. ${ }^{[11]}$ This is mostly caused by lack of knowledge and skills and lack of confidence of nursing and midwifery educators in simulating the clinical procedures to students. It is imperative that training institutions ensure that nursing and midwives' educators are equipped with simulation training knowledge and skills. The results of this study have demonstrated that simulation training for nursing and midwifery educators is a valuable method that enhances team working, communication and planning. Furthermore, it is clear that simulation training cannot replace real-lifework-based experience, but it may be used to augment knowledge and competencies to enhance patient safety. The finding of this study reported that the majority of the participants were aged 31 to 49 years. This is a middle age working category that can effectively conduct simulations. All participants were female which implies that nursing and midwifery profession originally is more domi- nated by women than men. According to Catling et al., ${ }^{[12]}$ midwifery is traditionally female profession. However, in recent years, men are increasing in the nursing and midwifery profession compared to previous years. All participants reported prior experiences as simulation participants and the majority were giving simulation training to their students at least weekly. These study findings are similar with the study by LaFond et al. ${ }^{[13]}$ (2016) on their study among twenty clinical nurse educators and clinical nurse specialists from the Center for Nursing Professional Practice and Research.

The majority of the participants indicated that the teaching methods used in the simulation training were helpful and they were provided with different learning materials to promote and motivate their learning. Similarly, Avila-Alvareze et al. ${ }^{[14]}$ conducted a study by evaluating participants' feedback after a simulation-based training in neonatal resuscitation using a realistic delivery room in Coruña University Hospital, in Spain. Majority of the participants $(87.5 \%)$ reported that the scenarios simulated seemed real like in real clinical situations and the room properly simulated a real delivery room. Therefore, participants felt that they were equipped with simulation knowledge and skills, and the course improved their ability to work in a team.

The current findings indicated that $30 \%$ of the participants strongly agreed and $60 \%$ agreed that they felt confident to debrief during simulation. Debriefing is an essential aspect of simulation, which should receive as much attention as the resolution of the scenario. ${ }^{[15]}$ According to Mariani et al., ${ }^{[16]}$ debriefing foster and enhance critical thinking skills through the practice of psychomotor skills and therapeutic communication techniques. This is further supported by a study conducted by Glesmann et al. ${ }^{[17]}$ which indicated that debriefing immediately after the simulation help students to decompress and integrate the experience into their knowledge base.

The current study findings showed that participants' knowledge and skill were increased and their attitudes toward simulation were improved. Improved knowledge and skill in simulation training among educators is important because trainers will use those gained skills during simulation for students. Students will be able to grasp what is simulated which consequently improves patient care. The findings were consistent with prior research done by Zhao et al. ${ }^{[9]}$ The study results imply that participants will be able to transfer knowledge and skills to their students.

Current study participants also indicated that they gain selfconfidence in learning. In contrast, a study conducted by LaFond and Blood ${ }^{[13]}$ among NPD specialists, participants reported that they were least confident in choosing simula- 
tions to align with learning objectives. According to Bandura theory of learning, ${ }^{[18]}$ student will develop self-confidence based their ability to succeed, thus would influence the effort they will put forth when confronted with a task and how long they will persevere when confronted with obstacles. However, several studies have shown that repeated simulation in real life has been linked with improved selfconfidence, hence allow students the opportunity to practise clinical skills and improve decision making in an effort to develop confidence in their own aptitudes. ${ }^{[11,19,20]}$ According to Cummings et al. ${ }^{[21]}$ Cummings and Connelly, repeated simulation experiences could lead to an increase in student self-confidence and active learning.

\section{CONCLUSiOnAND RECOMMENDATIONS}

It was concluded that simulation training for midwifery trainers is an important aspect in the midwifery professional de- velopment. Midwifery trainers need to be trained on simulation training so that they acquire up to date knowledge and skills which they can share to their students. The study has also revealed that simulation training for midwifery trainers can positively influence knowledge and skills.. Participants have indicated that they have gained knowledge and skill and indicated their confidence in performing simulation training with their students. Increasing simulation based training will improve competency and confidence among students and enhance patients' safety. Therefore, it is recommended to conduct other studies on simulation based training in Namibia, since this was the first study on simulation training in Namibia.

\section{CONFLicts OF INTEREST Disclosure}

The authors declare that there is no conflict of interest.

\section{REFERENCES}

[1] Coffey F. Learning by simulation - is it a useful tool for midwifery education? New Zealand College of Midwives Journal. 2015; (51): 3036. https://doi.org/10.12784/nzcomjn151.2015.5.30-36

[2] Li AML. Simulation-Based Clinical Skill Training to Promote Effective Clinical Learning with Simulation Evaluation Rubrics in Nursing Education. International Journal of Information and Education Technology. 2016. https://doi .org/10.7763/IJIET . 2016.V6.69 2

[3] Fowler-Durham C, Alden R. Enhancing Patient Safety in Nursing Education Through Patient Simulation . In book: Patient Safety and Quality: An Evidence-Based Handbook for Nurses Chapter: Chapter 51. Agency for Healthcare Research and Quality (US). 2012.

[4] Deegan M, Terry L. Student midwives' perceptions of real-time simulation: A qualitative phenomenological study. British Journal of Midwifery. 2013; 21(8). https://doi.org/10.12968/bjom. 20 13.21 .8 .590

[5] Gudayu TW, Badi MB, Melkamu M. Self-Efficacy, Learner Satisfaction, and Associated Factors of Simulation Based Education among Midwifery Students: A Cross-Sectional Study. Education Research International. 2015. https ://doi .org/10.1155/2015/346182

[6] Maskálová E, Urbanová E, Bašková M, et al. Experience of lecturers with simulation training in midwifery education in Slovakia. Midwifery. 2018; 59: 1-3. PMid:29331775 https://doi .org/10.101 6/j.midw. 2018.01.001

[7] Kumar A, Nestel D, Hay M, et al. The Australian \& New Zealand Journal of Obstetrics \& Gynaecology. 2018; 58(1): 40-46.

[8] Lendahls L, Oscarsson MG. Midwifery students' experiences of simulation- and skills training. Nurse Education Today. 2017; 50: $12-$ 16. PMid:28006699 https ://doi .org/10.1016/j . nedt . 2016. 12.005

[9] Zhao Y, Hu Y, Liang J, et al. A pilot study on the simulationbased training for Ethiopia skilled birth attendants. Nurse Education in Practice. 2019; 34(1): 130-138. PMid:30529835 https: //doi.org/10.1016/j.nepr.2018.12.001
[10] Li AML. Simulation-Based Clinical Skill Training to Promote Effective Clinical Learning with Simulation Evaluation Rubrics in Nursing Education. International Journal of Information and Education Technology. 2016; 6(3): 237-242. https://doi.org/10.7763/IJIE T.2016.V6.692

[11] Vermeulen J, Beeckman K, Turcksin R, et al. The experiences of last-year student midwives with High-Fidelity Perinatal Simulation training: A qualitative descriptive study. Journal of The Australian College of Midwives. 2017; 30(3): 253-261. PMid:28341585 https://doi.org/10.1016/j.wombi.2017.02.014

[12] Catling C, Hogan R, Fox D, et al. Simulation workshops with first year midwifery students. Nurse Education In Practice. 2016; 17: 10915. PMid:26777872 https://doi .org/10.1016/j.nepr. 2015. 12.003

[13] LaFond CM, CCRN-Ka, Blood A. Targeted Simulation Instructor Course for Nursing Professional Development SpecialistsAttribution. J Nurses Prof Dev. 2016; 32(6): 284-293. PMid:27846078 https://doi.org/10.1097/NND.0000000000000306

[14] Avila-Alvarez e A, Gonzalez-Rivera IJL, Fernandez T, et al. Evaluation of participants' feedback after a simulation-based training in neonatal resuscitation using a realistic delivery room. Open Journal of Pediatrics. 2012; 2: 281-287. https://doi .org/10.4236/oj ped.2012.24047

[15] Coutinho VRD, Martins JCA, Pereira MFCR. Construction and Validation of the Simulation Debriefing Assessment Scale Revista de Enfermagem Referência. 2014.

[16] Mariani B, Cantrell MA, Meakim C, et al. Structured Debriefing and Students' Clinical Judgment Abilities in Simulation. Clinical Simulation in Nursing. 2013; (9): e147-e155. https://doi.org/ 10.1016/j. ecns. 2011.11.009

[17] Glesmann SA, Kastner A, Venteicher M. Evaluating debriefing methods for high fidelity simulation :An Evidence-Based Project. Masters thesis. Nebraska Methodist College. Omaha, Nebraska. 2016. Available from: https://sigma. nursingrepository.or $\mathrm{g} /$ bitstream/handle/10755/620639/EvaluatingMethodsf orSimulationDebriefing. pdf? sequence=3\&isAllowed=y 
[18] Bandura A. Self-efficacy: The exercise of control. New York: Worth. 1997.

[19] Tosterud R, Hedelin B, Hall-Lord M. Nursing students' perceptions of high andlow fidelity simulation used as learning methods. Nursing Education in Practice. 2013; 13: 262-270. PMid:23454066 https://doi.org/10.1016/j.nepr.2013.02.002

[20] Handley R, Doege N. Can simulated clinical practice learning improve clinical competence? British Journal of Nursing. 2013; 22(9): 529-535. PMid:23819196 https://doi .org/10.12968/b jon.2013.22.9.529

[21] Cummings CL, Connelly LK. Can nursing students' confidence levels increase with repeated simulation activities?. Nurse Education Today. 2016; 36: 419-421. PMid:26599594 https ://doi.org/10 $.1016 / j$.nedt .2015 .11 .004 